\title{
Designing the cumulative indicators and criteria for educational process subjects competence assessment
}

\author{
Olga Marukhina, Olga Berestneva, \\ Elena Mokina, Elena Berestneva \\ Engineering School of IT and Robotics, \\ National Research Tomsk Polytechnic University \\ Tomsk, Russia \\ Marukhina@tpu.ru
}

\author{
Natalia Kozlova \\ Dept. of Genetic and Clinical Psychology, \\ National Research Tomsk State University \\ Tomsk, Russia
}

\begin{abstract}
This article shows different kinds of cumulative indicators in various fields of knowledge are widely used for the object's status or processes assessment. Its main purpose is to give a comprehensive assessment the selected object characteristics. Such indicators are easy to use and serve as a kind of sensors as their deviations from certain given values indicate changes in state of the object and its suggested further analysis. The indicator sensitivity to an object state changing at different levels of its hierarchy is directly connected with the choice of the object decomposition level on which the integral component constructed.
\end{abstract}

Keywords-integral criteria, methods of artificial intelligence, information technology.

\section{INTRODUCTION}

All local estimates in some area (time, spatial, situational) can be summarized in one global cumulative indicator. Local estimates are any quantitative assessments that are made on the basis of single measurement at a single point at some point in time, the point in the geometric space or state space. Formally, this aspect can be written as follows. Let all of estimates are contained in the set of points $z_{1}, z_{2}, \ldots, z_{n}: Z=\left\{z_{i}\right\}$. Each local estimate $h$, which is measured on each element, is $h\left(z_{i}\right)$. If the set $Z$ is continuous, cumulative indicator can be written as the integral $H=\int h(Z) d Z$.

In accordance with the particular task the variety of methods and approaches have been used. The qualimetry models [1], methods for producing cumulative estimates of the human body state [2,3], cumulative estimates of professional readiness [4] and professional suitability [5] were used as basic. For the cumulative estimates and criteria formation for competency assessment the methods were chosen on the basis of the coagulation types methods analysis which are used in the qualimetry models. Cumulative estimates which were proposed can be divided into 4 types according to the used type convolution (Table 1). The criteria from Table 1 can be used for tasks related to the assessment of students' competence (for example, the academic ranking); and be included as the part of the decision rules for competence diagnose. Cumulative estimates and criteria formation algorithm for assessing students' competence components which based on the factor models are presented below.

TABLE I. CUMULATIVE ESTIMATES AND COMPETENCY EVALUATION CRITERIA

\begin{tabular}{|c|c|c|}
\hline Convolution types & $\begin{array}{l}\text { Cumulative } \\
\text { estimates and } \\
\text { criteria types }\end{array}$ & $\begin{array}{l}\text { The estimated } \\
\text { components of } \\
\text { competencies } \\
\text { and tasks }\end{array}$ \\
\hline $\begin{array}{l}\text { Functional convolution } \\
\bar{\mu}=f\left(\mu_{1}, \ldots, \mu_{n}\right)\end{array}$ & $\begin{array}{l}\text { Formal criteria as } \\
\text { factor models }\end{array}$ & \multirow{2}{*}{$\begin{array}{l}\text { Cumulative } \\
\text { estimates for } \\
\text { personal and } \\
\text { business skills } \\
\text { assessment } \\
\text { (entrepreneurial } \\
\text { skills, teaching } \\
\text { abilities, etc.) }\end{array}$} \\
\hline $\begin{array}{l}\text { Separable convolution } \\
\bar{\mu}=\sum l\left(\lambda_{i}\right) \varphi\left(\mu_{i}\right)\end{array}$ & $\begin{array}{l}\text { The adherence } \\
\text { functions in form of } \\
\text { membership } \\
\text { functions }\end{array}$ & \\
\hline $\begin{array}{l}\text { Additive convolution } \\
\bar{\mu}=\sum \lambda_{i} \mu_{i}\end{array}$ & $\begin{array}{l}\text { Formal criteria as } \\
\text { factor models }\end{array}$ & $\begin{array}{l}\text { Cumulative } \\
\text { estimates for } \\
\text { personal and } \\
\text { business skills } \\
\text { assessment } \\
\text { (entrepreneurial } \\
\text { skills, teaching } \\
\text { abilities, etc.) }\end{array}$ \\
\hline $\begin{array}{l}\text { Alternative } \begin{array}{l}\text { conjunctive } \\
\text { coagulation: convolution }\end{array} \\
\text { bivalent alternative quality } \\
\text { measures }\{0 ; 1\} \text { as a } \\
\text { conjunction of predicates } \\
\text { suitability (the "suitable" - 1; } \\
\text { "not suitable" - } 0 \text { ). }\end{array}$ & $\begin{array}{c}\text { Cumulative criteria } \\
\text { as the production } \\
\text { models }\end{array}$ & $\begin{array}{l}\text { Professional } \\
\text { suitability } \\
\text { Integral criteria } \\
\text { for a variety of } \\
\text { University } \\
\text { technical } \\
\text { specialties }\end{array}$ \\
\hline
\end{tabular}

\section{FORMAL CRITERIA AS FACTOR MODELS}

Authors [6] demonstrated factor models in the cumulative estimate formation for assessing personal qualities. We use this approach for the cumulative estimates formation for assessing different types of competence (competence model components).

Wide interest in the factor analysis methods application is related to the fact that these methods allow to solve a problem of a classification scheme construction, i.e. compact meaningful description of the phenomenon under investigation, based on the processing of large data arrays. The basic factor analysis model is recorded as the following system of equations 


$$
x_{i}=\sum l_{i j} f_{i}+\varepsilon_{i} ; \quad i=\overline{1, p} ; \quad m \leq p .
$$

Each characteristic value $x_{i}$ can be expressed as amount of simple factors $f_{i}$ whose number is less than the number of initial characteristics and a residual member $\varepsilon_{i}$, dispersion $\sigma^{2}$ acting only on $x_{i}$, which is called specific factor. $l_{i j}$ - loadings from $i$-th variable on factor $j$-th or $j$-th factors loading on the $i$ th variable. Maximum possible number of factors $m$ in a given number of attributes $p$ defined by the inequality $(p+m) \leq(p-$ $m)^{2}$ which must be satisfied that the task does not degenerate into the trivial. This inequality is obtained by counting the freedom degrees available in the problem. Factor's analysis task can not be resolved uniquely. Equalities 1 is not amenable to direct verification, as the $\mathrm{p}$ initial signs given by other $(p+$ $m$ ) variables - simple and specific factors. Therefore, the representation of the correlation matrix factors can produce an infinite number of ways. If it were able to produce a correlation matrix factorization using a matrix of factor loadings $F$, then any linear orthogonal transformation $F$ (orthogonal rotation) lead to the same factorization.

Authors used orthogonal rotation factors which are realised by varimax method. This method was chosen because it allows to simplify the interpretation of factors (while quartimaks - variables and ekvamaks - and factors and variables simultaneously). These factors are linear functions of the form:

$$
\begin{gathered}
F_{i}=f_{11} \cdot x_{1}+f_{12} \cdot x_{2}+\ldots+f_{1 p} \cdot x_{p} \\
i=\overline{1, m ;} \quad j=1,2, . . p .
\end{gathered}
$$

where $x_{i}$-variables; $m$ - number of factors; $p$ - number of variable; $f_{i j}-i$-th factors loading on the $j$-th variable. Function as (2) was used as a formal criterion for assessing the quality of the educational process objects. This approach is most effective when the object under study is characterized by a kind of output quality $Y$, which is determined apriori (not necessarily unique) by the set of identifiable and measurable "inputs" $x_{1}, x_{2}, \ldots, x_{p}$. For example, the level of pedagogical skill $Y$ is characterized by signs of $x_{1}, x_{2}, \ldots, x_{p}$ that can be "measured" by the results of the students questionnaire survey.

This approach is demonstrated on the example of the generalized criteria's formation for evaluating and analyzing the special competence's structure for the technical college graduates who are involved in the teaching activities. Professional activity sphere for technical colleges graduates is quite diverse; inter alia it includes some teaching activities (mainly related to the teaching of special subjects).

In this study, the students acted as experts. They took part in questionnaire survey "As students see the teacher". These responses were used as expert estimates. This questionnaire is used in the Tomsk Polytechnic University and a number of other Russian universities when the certification of teachers. But the standard method of processing and analyzing the results for this questionnaire is incorrect from the viewpoint of mathematical statistics. For example, can not use the average value as a measure of central tendency for the rank scale's measurements. Also, outlying observations are not considered (estimates of experts - "heretics") in the final evaluation, etc. In this regard, for the analysis and processing of the survey results were used expert and statistical algorithms developed by authors [7].

Presentation of above algorithms is presented below on the example of the processing and analysis survey results for senior students one of the Tomsk Polytechnic University departments. Students evaluated teachers providing educational disciplines related to the future profession. There were evaluated: Group 1: 16 teachers (the set \{P1,P3,P4.....P17\}); Group 2: 13 teachers (the set $\{\mathrm{P} 1, \mathrm{P} 2, \mathrm{P} 3 \ldots . . \mathrm{P} 13\})$. According to the questionnaire, it was necessary to evaluate on a 9-point scale, 18 properties (valued

\begin{tabular}{|c|c|c|c|c|c|}
\hline \multirow[t]{2}{*}{ Estimated indicator } & \multicolumn{2}{|c|}{$\begin{array}{l}\text { The number } \\
\text { of "heretics" }\end{array}$} & \multirow[t]{2}{*}{$\begin{array}{c}\text { The } \\
\text { number of } \\
\text { "heretics" }\end{array}$} & \multicolumn{2}{|c|}{$\begin{array}{c}\text { After } \\
\text { exclusion of } \\
\text { "heretics" }\end{array}$} \\
\hline & $M e$ & $W_{0}$ & & Me & $W_{1}$ \\
\hline $\begin{array}{l}\text { 1. He/she presents the } \\
\text { teaching material clearly, } \\
\text { available for students }\end{array}$ & 6 & 0.437 & 7 & 6.5 & 0.719 \\
\hline $\begin{array}{l}\text { 2. Explains difficult } \\
\text { moments }\end{array}$ & 5.5 & 0.596 & 3 & 6 & 0.620 \\
\hline $\begin{array}{l}\text { 3. Highlights the main } \\
\text { points }\end{array}$ & 5.5 & 0.611 & 4 & 6 & 0.798 \\
\hline $\begin{array}{l}\text { 4. He/she is able to induce } \\
\text { and maintain audience } \\
\text { interest }\end{array}$ & 5 & 0.394 & 4 & 5 & 0.410 \\
\hline $\begin{array}{l}\text { 5. Monitoring the } \\
\text { audience's reaction }\end{array}$ & 5 & 0.568 & 6 & 5.5 & 0.662 \\
\hline $\begin{array}{l}\text { 6. Asks questions to } \\
\text { encourage discussion }\end{array}$ & 5.5 & 0.626 & 1 & 5.5 & 0.649 \\
\hline $\begin{array}{l}\text { 7. Follows the logic in the } \\
\text { presentation }\end{array}$ & 6.5 & 0.579 & 1 & 6.5 & 0.597 \\
\hline $\begin{array}{l}\text { 8. Demonstrates speech } \\
\text { culture, clarity of diction, } \\
\text { normal rate of presentation }\end{array}$ & 6 & 0.713 & 1 & 6 & 0.719 \\
\hline $\begin{array}{l}\text { 9. He/she able to relieve } \\
\text { tension and fatigue } \\
\text { audience }\end{array}$ & 5 & 0.632 & 3 & 5 & 0.743 \\
\hline $\begin{array}{l}10 . \mathrm{He} / \text { she is able to orient } \\
\text { students on the use of the } \\
\text { material studied in future } \\
\text { work }\end{array}$ & 4.5 & 0.650 & 10 & 5 & 0.768 \\
\hline $\begin{array}{l}\text { 11. Creativity and interest } \\
\text { in the work }\end{array}$ & 6 & 0.500 & 5 & 6.5 & 0.542 \\
\hline $\begin{array}{l}\text { 12. Friendliness in dealing } \\
\text { with students }\end{array}$ & 4.5 & 0.654 & 5 & 6 & 0.792 \\
\hline 13. Patience & 6.5 & 0.354 & 6 & 7 & 0.425 \\
\hline 14. Exactingness & 6 & 0.587 & 5 & 7 & 0.663 \\
\hline $\begin{array}{l}\text { 15. Interest in student } \\
\text { success }\end{array}$ & 4.5 & 0.493 & 8 & 6 & 0.589 \\
\hline $\begin{array}{l}\text { 16. Objectivity in the } \\
\text { assessment of knowledge }\end{array}$ & 6 & 0.608 & 7 & 6.5 & 0.754 \\
\hline 17. Respect for students & 6 & 0.564 & 8 & 7 & 0.654 \\
\hline $\begin{array}{l}\text { 18. High erudition, } \\
\text { demeanor, appearance }\end{array}$ & 6 & 0.654 & 8 & 7 & 0.754 \\
\hline
\end{tabular}
qualities are presented in Table 2).

TABLE II. THE RESULTS OF THE EXPERT ESTIMATING

Y_Personality - criterion for assessing the teachers personal qualities:

$Y \_$Personality $=0,93 x_{9}+0,73 x_{12}+0,60 x_{13}+0,54 x_{18}$; 
Y_ProfCompetence - criterion assessing the teachers professional competence:

Y_ProfCompetence $=0,86 x_{10}+0,51 x_{11}$

TABLE III. FACTOR LOADINGS

\begin{tabular}{|l|c|c|c|}
\hline \multicolumn{1}{|c|}{ Variables (indicators) } & \multicolumn{3}{|c|}{ Factors } \\
\cline { 2 - 4 } & Factor 1 & Factor 2 & Factor 3 \\
\hline $\begin{array}{l}\text { 1. He/she presents the teaching } \\
\text { material clearly, available for } \\
\text { students }\end{array}$ & 0.87 & 0.12 & 0.11 \\
\hline 2. Explains difficult moments & 0.87 & 0.04 & 0.12 \\
\hline 3. Highlights the main points & 0.92 & -0.25 & 0.04 \\
\hline $\begin{array}{l}\text { 4. He/she is able to induce and } \\
\text { maintain audience interest }\end{array}$ & 0.83 & -0.24 & -0.25 \\
\hline $\begin{array}{l}\text { 5. Monitoring the audience's } \\
\text { reaction }\end{array}$ & 0.88 & 0.02 & -0.24 \\
\hline $\begin{array}{l}\text { 6. Asks questions to encourage } \\
\text { discussion }\end{array}$ & 0.78 & 0.06 & 0.02 \\
\hline $\begin{array}{l}\text { 7. Follows the logic in the } \\
\text { presentation }\end{array}$ & 0.89 & -0.34 & 0.06 \\
\hline $\begin{array}{l}\text { 8. Demonstrates speech culture, } \\
\text { clarity of diction, normal rate of } \\
\text { presentation }\end{array}$ & 0.68 & 0.93 & -0.34 \\
\hline $\begin{array}{l}\text { 9. He/she able to relieve tension and } \\
\text { fatigue audience }\end{array}$ & -0.06 & -0.02 & 0.93 \\
\hline $\begin{array}{l}\text { 10. He/she is able to orient students } \\
\text { on the use of the material studied in } \\
\text { future work }\end{array}$ & 0.21 & 0.24 & -0.02 \\
\hline $\begin{array}{l}\text { 11. Creativity and interest in the } \\
\text { work }\end{array}$ & 0.19 & 0.73 & 0.24 \\
\hline $\begin{array}{l}\text { 12. Friendliness in dealing with } \\
\text { students }\end{array}$ & -0.28 & 0.60 & 0.73 \\
\hline 13. Patience & 0.12 & -0.39 & 0.60 \\
\hline 14. Exactingness & 0.79 & 0.11 & -0.39 \\
\hline 15. Interest in student success & 0.01 & 0.07 & 0.11 \\
\hline $\begin{array}{l}\text { 16. Objectivity in the assessment of } \\
\text { knowledge }\end{array}$ & 0.39 & -0.32 & 0.07 \\
\hline 17. Respect for students & 0.41 & 0.54 & -0.32 \\
\hline $\begin{array}{l}\text { 18. High erudition, demeanor, } \\
\text { appearance }\end{array}$ & -0.41 & 0.54 & 0.34 \\
\hline
\end{tabular}

In [8-10], are presented the experimental effectiveness verification of the developed formal criteria.

\section{DECISION MAKING ON THE FUZZY MODELS BASED}

The issue of objects selection and their ordering in the context of education occurs quite often, and we can list a number of practical problems associated with this issue $[8,11]$ :

1. Detection of students at the risk of psychophysiological and social exclusion (at-risk students)

2. The competitive selection for postgraduate studies and Master's degree

3. The selection of students, having completed Bachelor's programme, for the next level of study (engineer training)

4. The competitive selection of young scientists for the candidate pool

5. The formation of the database on graduates according to the available vacancies

6. The occupational guidance for prospective students (selection of the most suitable department) and the competitive selection (by additional criteria) among applicants with equal score on the results of entrance examinations

7. The competitive selection of students to study at the reserve-officer training department.

For these problems solving the authors have employed different methods and approaches, one of which is presented in this article. In the performance of the task of objects selection the original set $\mathrm{X}$ is divided into two classes: the class of admissible objects (feasible set) and a class of inadmissible objects. The utility value of objects is estimated on the basis of their characteristic symptoms.

In the case of the selection of non-dominated objects the precedence of one object over another is given only in case, when according to all criteria the first object (dominating) is not worse than the second object (dominated), and is better concerning at least one of criteria given. The set consisting of non-dominated objects is called the Pareto set. Algorithms for finding the Pareto set and limitations for the use of this method are detailed in [9].

In [9] for further ordering of objects included in the Pareto set it is proposed to use the apparatus of the fuzzy-set theory. In addition, the results of our studies, as well as analysis of other authors' works on the issue of selection and ordering of objects, whose signs turn up to be the elements and components of competence, have shown that the use of fuzzy models and algorithms of fuzzy logic is considered to be the most promising approach.

For further discussion it counts to provide a number of definitions and principles of the fuzzy-set theory and fuzzy logic, so let us briefly consider such concepts such as fuzzy rule and fuzzy inference.

In the fuzzy logic values of all variables are not represented by numbers but by words of a natural language and are called terms. Thus, to define the value of such linguistic variable as intellect the terms very high, high, medium, and so on can be used. Figure 1 shows the example illustrating the definition of the terms for such variable as intelligence quotient (IQ).

The determination of the precise physical values of the terms are regarded necessary to implement a linguistic variable. Suppose, for example, the variable intelligence (IQ) can take any value ranging from 60 to 140 points according to Amthauer's Intelligence Structure Test.

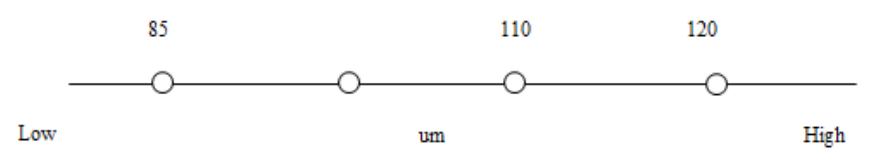

Fig. 1. Term range for the variable intelligence (IQ)

According to the fuzzy set theory, each value of IQ within the range of 140 points can be associated with a number from zero to one, which determines the degree of membership of the IQ value (for example, 100 points) to a particular term of the linguistic variable intellect. In our case, the IQ 120 point 
coefficient demonstrates the degree of membership to the term very high, equal to 0.85 and to the term medium equal to 0,15 . The precise definition of the degree of membership is only possible when working with experts.

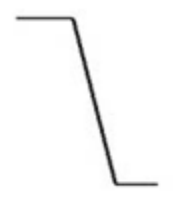

Z-function

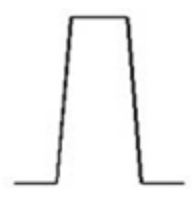

$\Pi$-function

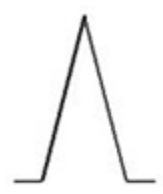

J-function

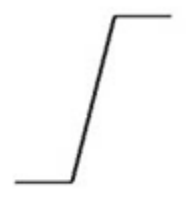

S-function
Fig. 2. Standard membership functions

The membership of each precise value to one of the terms of the linguistic variable is determined by the membership function. It can be of any model, however the concept of the so-called standard membership functions has been recently formed (Fig.2). These standard membership functions can be easily applicable to most problem solving. We will use the method based on the interval estimates to construct the membership function.

The theory of possibilities is based on the assumption that there is an interval of criterion value of $h\left[h^{*}, h^{0}\right]$, which corresponds to the concept of a 'good' object, and the boundary interval values have the following interpretation. Suppose $h^{a}$ is the result of the measurement of the characteristic $h$ of the object $a$, then $h^{a}$ is the boundary of an ideal area, i.e. if $h^{a} \geq h^{*}$, the object must be considered to be the perfect correspondence to the concept of 'good'. The possibility of such statement $\mu(u)=1$ (where $u$ is a subjective event coming from the expert's viewpoint that the object is in a 'good' state). In case $h^{a} \leq h^{0}$, the situation is interpreted as follows: the possibility that the object is 'good' $\mu(u)=0$. Obviously, when $h^{0}<h^{a}<h^{*}$, the possibilities have values $0<\mu(u)<1$.

It is evident that with the approach of $h^{a}$ to the boundary $h^{*}$ the possibility of regarding $a$ a 'good' object increases linearly (Fig. 3). At the same time for determination of the membership function the following formula:

$$
\mu(u)=\left\{\begin{array}{ccc}
0, & \text { if } & h^{a} \leq h^{0} ; \\
\frac{h^{a}-h^{0}}{h^{*}-h^{0},} & \text { if } & h^{0}<h^{a} \leq h^{*} \\
1, & \text { if } & h^{a} \geq h^{*} .
\end{array}\right.
$$

Table 1 shows threshold values of $h^{0}$ and $h^{*}$ for some elements of subject-activity competence, which are obtained from the study of literature and our own research $[12,13]$. In [11] the methods of alternatives selection in terms of fuzziness and our own developed algorithms on the basis of these methods are being considered. As the main decision-making criterion the minimax approach is used, it is necessary to dwell on this issue in more detail. $\mu(u)$

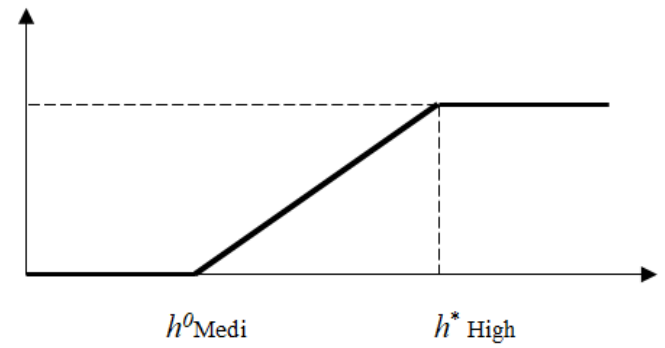

Fig. 3. Graphic representation of membership function

TABLE IV. THRESHOLD VALUES OF $\mathrm{H}^{0}$ AND H* OF PSYCHOGNOSTIC INDICATORS

\begin{tabular}{|c|c|c|c|c|c|c|c|}
\hline \multirow[t]{2}{*}{$\begin{array}{l}\text { Indicators of } \\
\text { psychological } \\
\text { testing }\end{array}$} & & \multicolumn{2}{|c|}{$\begin{array}{l}\text { Faculty of } \\
\text { Cybernetics }\end{array}$} & \multicolumn{2}{|c|}{$\begin{array}{l}\text { Faculty of } \\
\text { Mechanical } \\
\text { Engineering }\end{array}$} & \multicolumn{2}{|c|}{$\begin{array}{l}\text { Faculty of } \\
\text { Humanities }\end{array}$} \\
\hline & & ho & $h^{*}$ & ho & $h^{*}$ & ho & $h^{*}$ \\
\hline $\begin{array}{l}\text { Verbal } \\
\text { intelligence }\end{array}$ & IQ1 & 90 & 120 & 80 & 115 & 100 & 125 \\
\hline Numeracy & IQ5 & 100 & 125 & 90 & 115 & 80 & 110 \\
\hline $\begin{array}{l}\text { Mechanical } \\
\text { intelligence }\end{array}$ & IQ6 & 100 & 125 & 105 & 125 & 80 & 100 \\
\hline $\begin{array}{l}\text { Combinatorial } \\
\text { thinking }\end{array}$ & IQ7 & 100 & 125 & 105 & 125 & 85 & 105 \\
\hline $\begin{array}{l}\text { Spatial } \\
\text { perception }\end{array}$ & IQ8 & 80 & 110 & 95 & 125 & 90 & 115 \\
\hline $\begin{array}{l}\text { The ability to } \\
\text { memorize and } \\
\text { reproduce } \\
\text { information }\end{array}$ & IQ9 & 85 & 115 & 90 & 115 & 95 & 125 \\
\hline $\begin{array}{l}\text { Communicativ } \\
\text { e skills }\end{array}$ & A & 3 & 8 & 4 & 8 & 6 & 10 \\
\hline $\begin{array}{l}\text { Logical } \\
\text { thinking }\end{array}$ & B & 6 & 10 & 5 & 8 & 4 & 8 \\
\hline Creativity & $\mathrm{M}$ & 5 & 9 & 3 & 7 & 4 & 8 \\
\hline $\begin{array}{l}\text { The ability to } \\
\text { give } \\
\text { nonstandard } \\
\text { solutions }\end{array}$ & Q1 & 3 & 11 & 2 & 10 & 2 & 8 \\
\hline
\end{tabular}

Note: IQ1, IQ5, IQ6, IQ7, IQ8, IQ9 - Amthauer's Intelligence Structure Test indicators; $A, B, M, Q 1-$ Cattell's 16 Personality Factors Test indicators.

\section{DECISION-MAKING ON THE BASIS OF THE MINIMAX CRITERION}

The decision-making represents the selection of one option from the set of variants under consideration: $E_{i} \in E$. Each $E_{i}$ determines a certain result $e_{i}$. The purpose is to select the variant with the maximal result $\max _{i} e_{i}$. In addition it is assumed that estimates $e_{i}$ characterize such variables as benefit, reliability and usefulness. The opposite situation is examined similarly by minimizing the estimate or by analyzing the negative utility. Thus, the choice of the best variant is performed by using the criterion [12]:

$$
E_{0}=\left\{E_{i 0} \mid E_{i 0} \in E \wedge e_{i 0}=\max _{i} e_{i}\right\}
$$


This choice law usually means the following: the set of optimal variants $E_{0}$ consists of those variants $E_{i 0}$ that belong to the set of variants $E$ and the estimate $e_{i 0}$ of which is maximal among all estimates $e_{i}$.

The maximum result $\max _{i} e_{i}$ can be achieved in the set of results repeatedly, so the choice of the optimal variant in accordance with the criterion (4) is not, generally speaking, unique as the necessity to choose one from several equally good solutions in practice does not usually cause any difficulties.

The case, when a decision in which each option corresponds to a unique external condition, is considered to be simple and quite common. In more complex structures, different external conditions (states) $F_{i}$ and decision results $e_{i j}$ may correspond to each valid variant $E_{i}$ due to various external conditions. In this case $e_{i j}$ is understood as having utility value, corresponding to variants $E_{i}$ and conditions $F_{i}$.

There are a lot of decision criteria: the minimax criterion, the Bayes-Laplace criterion, extended minimax criterion; the Hurwitz criterion; the Savage criteria and some others [12]. For instance, the minimax criterion (MM) uses the evaluation function corresponding to the position of extreme caution. At

$$
Z_{\text {MM }}=\max _{i} e_{i r} \text { и } e_{i r}=\min _{j} e_{i j}
$$

the relation is valid

$$
E_{0}=\left\{E_{i 0} \mid E_{i 0} \in E \wedge e_{i 0}=\max _{i} \min _{j} e_{i j}\right\}
$$

where $Z_{M M}$ is a valuation function of MM-criterion.

In accordance with MM-criterion the decision rule can be interpreted as follows. Decision matrix $\left\|e_{i j}\right\|$ is complemented with another column containing minimum results $e_{i r}$ of each line. The variants $E_{i o}$ having maximum value of $e_{i r}$ in the column should be chosen.

Selected in such a way variants eliminate the risk completely. This means that the decision maker cannot face a worse outcome than the one he is focusing. No matter what conditions $F_{i}$ occur, the result cannot be lower than $Z_{M M}$. This property makes the minimax criterion to be one of the fundamental ones [12], and that determined the choice of the criterion for the solution of the thesis work objective.

Decision-making is defined as choosing an alternative, which simultaneously satisfies the fuzzy goals and fuzzy constraints. In this regard, goals and constraints are symmetric with respect to the decision that blurs the distinction between them and allows to represent the solution as a fusion of fuzzy goals and constraints.

Having regard to the above, writing this work the modified algorithms for choosing alternatives under uncertainty were used to solve decision-making problems concerning the competence of students and graduates of the technical university [10]

\section{DECISION-MAKING ON THE BASIS OF THE MINIMAX CRITERION}

Let assume that next sets are known: $X=\left\{x_{1}, x_{2}, \ldots, x_{k}\right)$ is a variety of options, which are subject to multi-criteria analysis; $G=\left\{G_{1}, G_{2}, \ldots, G_{n}\right)$ is set of quantitative and qualitative criteria, which evaluates alternatives. The goal of multi-criteria analysis is ordering of $X$ elements according to the criteria of the set $G$. Let say that $\mu G_{i}\left(x_{j}\right)$ is a number in the range $[0,1]$, which character rizes the level of assessment options $x_{i} \in X$ by $G_{i} \in G$ criteria. The greater the number $\mu G_{i}\left(x_{j}\right)$, the higher score $x_{j}$ on the criterion $G_{i}, i=\overline{1, n}$, $j=\overline{1, k}$. Then the criterion $G_{i}$ can be written as:

$$
\bar{G}_{i}=\left\{\frac{\mu G_{i}\left(x_{1}\right)}{x_{1}}, \frac{\mu G_{i}\left(x_{2}\right)}{x_{2}}, \ldots, \frac{\mu G_{i}\left(x_{k}\right)}{x_{k}}\right\}
$$

where $\mu G_{i}\left(x_{j}\right)$ is degree of $x_{j}$ membership of $\bar{G}_{i}$ fuzzy set. To determine the degree of fuzzy sets we use the method of construction of membership functions on the basis of paired comparisons. To do this, create a matrix of pairwise comparisons of options for each criterion. The total number of such matrices matches the number of criteria and equals $n$. The best option will be the one that at the same time the best in all criteria. Fuzzy decision $\bar{D}$ is calculated as intersection of partial criteria:

$$
\begin{gathered}
D=\bar{G}_{1} \cap \bar{G}_{2} \cap \ldots \cap \bar{G}_{n}= \\
\left\{\frac{\min _{i=1, n} \mu G_{i}\left(x_{1}\right)}{x_{1}}, \frac{\min _{i=1, n} \mu G_{i}\left(x_{2}\right)}{x_{2}}, \ldots, \frac{\min _{i=1, n} \mu G_{i}\left(x_{k}\right)}{x_{k}}\right\}
\end{gathered}
$$

According to the obtained fuzzy set $\bar{D}$ the best option will be the one for which the degree of belonging is the greatest. Based on (8) we have next form if criteria have different ratio of importance:

$$
\bar{D}=\left\{\frac{\min _{i=1, n}\left(\mu G_{i}\left(x_{1}\right)\right)^{\alpha_{i}}}{x_{1}}, \ldots, \frac{\min _{i=1, n}\left(\mu G_{i}\left(x_{k}\right)\right)^{\alpha_{i}}}{x_{k}}\right\}
$$


where $a_{i}$ is relative ratio of importance criteria $G_{i}$, $\alpha_{1}+\alpha_{2}+\ldots+\alpha_{n}=1$. Exponent $\alpha_{i}$ in (9) indicates the concentration of fuzzy set ${ }^{-} G_{i}$ in accordance with importance ratio of criteria. Factors of relative importance criteria can be determined by various methods, for example by means of paired comparisons of Saatyscale.

\section{FUZZY MULTI-CRITERIA ANALYSIS OF THE APPLICANTS COMPETENCE FOR THE VACANT POSITION}

As an example of decision-making under fuzzy conditions according to the Bellman-Zadeh scheme, let us consider the comparison of professional levels of three technical university graduates $\left(x_{1}, x_{2}, x_{3}\right)$ applying for the same vacant position.

In order to assess the candidates' competence we use the following criteria: $G_{1}$ - expertise; $G_{2}$ - social competence; $G_{3}$ - communicative competence; $G_{4}$ - intellectual competence; $G_{5}$ - creativity; $G_{6}$ - innovation potential. When the expert compared applicants $\left(x_{1}, x_{2}, x_{3}\right)$ by criteria $\left(G_{1}, G_{2}, \ldots, G_{6}\right)$, the linguistic statements presented in Table 2 were obtained.

TABLE V. PAIRWISE COMPARISONS OF GRADUATES' COMPETENCE ACCORDING TO THE SAATY RATING SCALE

\begin{tabular}{|c|c|}
\hline Criterion & Pairwise comparison \\
\hline $\mathrm{G}_{1}$ & $\begin{array}{c}\text { Equal importance of } \mathrm{x}_{1} \text { and } \mathrm{x}_{2} \\
\text { Strong advantage of } \mathrm{x}_{3} \text { over } \mathrm{x}_{1}\end{array}$ \\
\hline $\mathrm{G}_{2}$ & $\begin{array}{c}\text { Moderate Plus advantage of } \mathrm{x}_{1} \text { over } \mathrm{x}_{3} \\
\text { Moderate advantage of } \mathrm{x}_{2} \text { over } \mathrm{x}_{3}\end{array}$ \\
\hline $\mathrm{G}_{3}$ & $\begin{array}{c}\text { Strong advantage of } \mathrm{x}_{1} \text { over } \mathrm{x}_{2} \\
\text { Extreme advantage of } \mathrm{x}_{1} \text { over } \mathrm{x}_{3}\end{array}$ \\
\hline $\mathrm{G}_{4}$ & $\begin{array}{c}\text { Moderate advantage of } \mathrm{x}_{2} \text { over } \mathrm{x}_{1} \\
\text { Slight advantage of } \mathrm{x}_{3} \text { over } \mathrm{x}_{1}\end{array}$ \\
\hline $\mathrm{G}_{5}$ & $\begin{array}{c}\text { Strong advantage of } \mathrm{x}_{1} \text { over } \mathrm{x}_{2} \\
\text { Demonstrated advantage of } \mathrm{x}_{1} \text { over } \mathrm{x}_{3}\end{array}$ \\
\hline $\mathrm{G}_{6}$ & $\begin{array}{c}\text { Moderate Plus advantage of } \mathrm{x}_{1} \text { over } \mathrm{x}_{2} \\
\text { Slight advantage of } \mathrm{x}_{3} \text { over } \mathrm{x}_{1}\end{array}$ \\
\hline
\end{tabular}

The given below matrix of pairwise comparisons $A\left(G_{i}\right)=\left\{x_{i j}\right\}$ corresponds to the expert statement:

$$
\begin{array}{rlrl}
A\left(G_{1}\right) & =\left[\begin{array}{ccc}
1 & 1 & 0.2 \\
1 & 1 & 0.2 \\
5 & 5 & 1
\end{array}\right], & & A\left(G_{2}\right)=\left[\begin{array}{ccc}
1 & 1.35 & 4 \\
0.75 & 1 & 3 \\
0.25 & 0.33 & 1
\end{array}\right], \\
A\left(G_{3}\right)=\left[\begin{array}{ccc}
1 & 5 & 7 \\
0.2 & 1 & 1.4 \\
0.14 & 0.71 & 1
\end{array}\right], & A\left(G_{4}\right)=\left[\begin{array}{ccc}
1 & 0.33 & 0.5 \\
3 & 1 & 1.5 \\
2 & 0.67 & 1
\end{array}\right], \\
A\left(G_{5}\right)=\left[\begin{array}{ccc}
1 & 5 & 6 \\
0.2 & 1 & 1.2 \\
0.17 & 0.83 & 1
\end{array}\right], & A\left(G_{6}\right)=\left[\begin{array}{ccc}
1 & 4 & 0.5 \\
0.25 & 1 & 0.13 \\
2 & 8 & 1
\end{array}\right] .
\end{array}
$$

Items matching pairwise comparisons from Table. 5 are shown in these matrices in semi-bold. Other elements have been found in the assumption of the compatibility of pairwise comparisons, i.e. taking into account that the matrix of pairwise comparisons is diagonal and has properties of transitivity and inverse symmetry.

$$
\begin{aligned}
& \bar{G}_{1}=\left\{\frac{0.14}{x_{1}}, \frac{0.14}{x_{2}}, \frac{0.72}{x_{3}}\right\}, \bar{G}_{2}=\left\{\frac{0.5}{x_{1}}, \frac{0.38}{x_{2}}, \frac{0.12}{x_{3}}\right\}, \\
& \bar{G}_{3}=\left\{\frac{0.74}{x_{1}}, \frac{0.15}{x_{2}}, \frac{0.11}{x_{3}}\right\}, \bar{G}_{4}=\left\{\frac{0.17}{x_{1}}, \frac{0.5}{x_{2}}, \frac{0.33}{x_{3}}\right\}, \\
& \bar{G}_{5}=\left\{\frac{0.73}{x_{1}}, \frac{0.15}{x_{2}}, \frac{0.12}{x_{3}}\right\}, \bar{G}_{6}=\left\{\frac{0.31}{x_{1}}, \frac{0.08}{x_{2}}, \frac{0.61}{x_{3}}\right\} .
\end{aligned}
$$

According to the formula (8) we obtain $\bar{D}=\left\{\frac{0.14}{x_{1}}, \frac{0.08}{x_{2}}, \frac{0.11}{x_{3}}\right\}$ which indicates a strong advantage of applicant $x_{1}$ over applicant $x_{2}$ and a moderate advantage of applicant $x_{1}$ over applicant $x_{3}$. Assume that the criteria for $G_{1}, G_{2}, \ldots, G_{6}$ are not in equilibrium. To determine the criterion ranking we use the method of pairwise comparisons and set the following linguistic statements concerning the importance of criteria:

- Moderate Plus advantage of $G_{2}$ over $G_{6}$

- Extreme advantage of $G_{3}$ over $G_{1}$

- Moderate advantage of $G_{3}$ over $G_{5}$

- Slight advantage of $G_{4}$ over $G_{6}$

- Equal importance of $G_{5}$ and $G_{6}$

The following matrix of pairwise comparisons $A=\left\{G_{i j}\right\}$ corresponds to the expert statements:

$$
A=\left[\begin{array}{cccccc}
1 & 0.25 & 0.14 & 0.21 & 0.43 & 0.43 \\
4 & 1 & 0.57 & 0.86 & 1.71 & 1.71 \\
7 & 1.75 & 1 & 1.5 & 3 & 3 \\
4.67 & 1.17 & 0.67 & 1 & 2 & 2 \\
2.33 & 0.58 & 0.33 & 0.5 & 1 & 1 \\
2.33 & 0.58 & 0.33 & 0.5 & 1 & 1
\end{array}\right]
$$

Let the criteria ranks $G_{1}, G_{2}, \ldots, G_{6}$ be defined as follows: $\quad \alpha_{1}=0.04 ; \quad \alpha_{2}=0.19 ; \quad \alpha_{3}=0.33 ; \quad \alpha_{4}=0.22$; $\alpha_{5}=0.11 ; \alpha_{6}=0.11$, which marks the communicative competence $\left(G_{3}\right)$ and intellectual competence $\left(G_{4}\right)$ to be of most importance. Using the (9) we obtain the fuzzy sets:

$$
\begin{aligned}
& \bar{G}_{1}=\left\{\frac{0.14^{0.04}}{x_{1}}, \frac{0.14^{0.04}}{x_{2}}, \frac{0.72^{0.04}}{x_{3}}\right\}=\left\{\frac{0.91}{x_{1}}, \frac{0.91}{x_{2}}, \frac{0.98}{x_{3}}\right\} ; \\
& \bar{G}_{2}=\left\{\frac{0.5^{0.19}}{x_{1}}, \frac{0.38^{0.19}}{x_{2}}, \frac{0.12^{0.19}}{x_{3}}\right\}=\left\{\frac{0.88}{x_{1}}, \frac{0.83}{x_{2}}, \frac{0.68}{x_{3}}\right\} ;
\end{aligned}
$$




$$
\begin{aligned}
& \bar{G}_{3}=\left\{\frac{0.74^{0.33}}{x_{1}}, \frac{0.15^{0.33}}{x_{2}}, \frac{0.11^{0.33}}{x_{3}}\right\}=\left\{\frac{0.91}{x_{1}}, \frac{0.53}{x_{2}}, \frac{0.48}{x_{3}}\right\} ; \\
& \bar{G}_{4}=\left\{\frac{0.17^{0.22}}{x_{1}}, \frac{0.5^{0.22}}{x_{2}}, \frac{0.33^{0.22}}{x_{3}}\right\}=\left\{\frac{0.68}{x_{1}}, \frac{0.86}{x_{2}}, \frac{0.79}{x_{3}}\right\} ; \\
& \bar{G}_{5}=\left\{\frac{0.73^{0.11}}{x_{1}}, \frac{0.15^{0.11}}{x_{2}}, \frac{0.12^{0.11}}{x_{3}}\right\}=\left\{\frac{0.97}{x_{1}}, \frac{0.81}{x_{2}}, \frac{0.79}{x_{3}}\right\} ; \\
& \bar{G}_{6}=\left\{\frac{0.31^{0.11}}{x_{1}}, \frac{0.08^{0.11}}{x_{2}}, \frac{0.61^{0.11}}{x_{3}}\right\}=\left\{\frac{0.88}{x_{1}}, \frac{0.76}{x_{2}}, \frac{0.95}{x_{3}}\right\} .
\end{aligned}
$$

As a result of the intersection of fuzzy sets $G_{1}, G_{2}, \ldots, G_{6}$ we get the following: $\bar{D}=\left\{\frac{0.68}{x_{1}}, \frac{0.53}{x_{2}}, \frac{0.48}{x_{3}}\right\}$, that demonstrates a strong advantage of graduate $x_{1}$ over the graduates $x_{2}$ and $x_{3}$, and a moderate advantage of graduate $x_{2}$ over the graduate $x_{3}$.

On the basis of the presented algorithm the authors developed a universal program COMPETENCE for evaluating the competence of professionals of any profile.

\section{CONCLUSION}

In conclusion are noted the following. Firstly, the cumulative indicators construction technology and criteria for competence estimates have been designed and demonstrated. On this criteria base the rating forming algorithms were developed. They allowing to minimize the role of the subjective factor in above tasks solution. Next, cumulative criteria which are derived from fuzzy set theory have been designed. The proposed approaches is demonstrated on practical examples.

\section{REFERENCES}

[1] Qualimetry and education: genesis, formation, development, problems and prospects (under ed Subetto, A.I.) In: 11th symposium
onQualimetry in education: methodology, methods and practice. Research center of problems of quality of training, Moscow (2006).

[2] Baevsky, R.M.: Prediction of states on the verge of norm and pathology. Medicine, Moscow (1997).

[3] Kaznacheev, V.P.: Essays on the theory and practice of human ecology. VP Treasurer, Nauka, Novosibirsk (1983).

[4] Kovalenko, A.V., Syromyatnikov, I.V.: Professionalism and its development as a scientific problem in psychology. In: Innovations in Education. vol. 10, pp. 58-70 (2008).

[5] Frunkin, A.A.: Psychological selection in professional and educational activities. Rech, St. Petersburg (2004)

[6] Ayvazyan, S.A.: Statistical research of dependencies. Metallurgia. Moscow (1968).

[7] Mokina, E.: Expert estimates in the informational support system of the university strategic plan. In: 8th Korea-Russia International Symposium on Science and Technology vol. 3, pp. 248-251 (2004).

[8] Berestneva, O.G., Marukhina, O.V., Benson, G.F., Zharkova, O.S.: Students competence assessment methods. In: Social and Behavioral Sciences, vol. 166, pp. 296-302 (2015).

[9] Maroukhine, O.V., Berestneva, O.G.: Expert support system for making decision by the results of computer-based testing within the ends of teaching quality evaluation In: 7th Korea-Russia International Symposium on Science and Technology (KORUS), pp. 416-419 (2003).

[10] Sharopin, K.A., Berestneva, O.G.: Expert system of an estimation of competence of students and graduates of technical university. In: 9th Russian-Korean International Symposium on Science and Technology, pp. 1098-1099. Novosibirsk (2005). doi: 10.1109/KORUS.2005.1507981.

[11] Hodashinsky, I., Meshcheriakov, R., Anfilofiev, A.: Identification of fuzzy classifiers based on weed optimization algorithm. In:1st Conference on Creativity in Intelligent Technologies and Data Science, CIT and DS (2015) vol.535, pp. 216-223 Springer (2015) doi:10.1007/978-3-319-23766-4 18.

[12] Dubinina, I.A., Berestneva, O.G., Sviridov, K.A.: Educational technologies for forming intellectual competence in scientific research and engineering business. In: Social and Behavioral Sciences, vol. 166, pp. 320-324 (2015).

[13] Kobyz, G.V., Zamyatin, A.V.: Conditional probability density estimation using artificial neural network In: 9th International Conference on Application of Information and Communication Technologies, AICT, pp. 441-445 (2015). doi: 10.1109/ICAICT.2015.7338597.

[14] Zamyatina, O.M., Mozgaleva, P.I., Marukhina, O.V., Goncharuk, Y.O. Game technogies in teaching "Mathematical modeling". In: Global Engineering Education Conference (EDUCON), pp. 847-851 IEEE Press, Tallinn Estonia (2015). doi: 10.1109/EDUCON.2015.7096071. 